\title{
Race predictors and hemodynamic alteration after an ultra-trail marathon race
}

This article was published in the following Dove Press journal:

Open Access Journal of Sports Medicine

6 October 2017

Number of times this article has been viewed

\section{Noppon Taksaudom ${ }^{\prime}$ \\ Natee Tongsiri \\ Amarit Potikul' \\ Chawakorn Leampriboon' \\ Apichat Tantraworasin' \\ Anong Chaiyasri'}

'Cardiovascular and Thoracic Surgery Unit, Department of Surgery, Chiang Mai University Hospital, ${ }^{2}$ Department of Mathematics, Faculty of Science, Chiang Mai University, Chiang Mai, Thailand
Correspondence: Noppon Taksaudom Department of Surgery, Maharaj Nakorn Chiang Mai Hospital, Faculty of Medicine, Chiang Mai University, Chiang Mai 50200, Thailand

Tel +66899938728

Email drnoppon@hotmail.com
Objective: Unique rough-terrain ultra-trail running races have increased in popularity. Concerns regarding the suitability of the candidates make it difficult for organizers to manage safety regulations. The purpose of this study was to identify possible race predictors and assess hemodynamic change after long endurance races.

Methods: We studied 228 runners who competed in a $66 \mathrm{~km}$-trail running race. A questionnaire and noninvasive hemodynamic flow assessment including blood pressure, heart rate, stroke volume, stroke volume variation, systemic vascular resistance, cardiac index, and oxygen saturation were used to determine physiologic alterations and to identify finish predictors. One hundred and thirty volunteers completed the questionnaire, 126 participants had a prerace hemodynamic assessment, and 33 of these participants completed a postrace assessment after crossing the finish line. The participants were divided into a finisher group and a nonfinisher group.

Results: The average age of all runners was 37 years (range of 24-56 years). Of the 228 runners, $163(71.5 \%)$ were male. There were $189(82.9 \%)$ finishers. Univariable analysis indicated that the finish predictors included male gender, longest distance ever run, faster running records, and lower diastolic pressure. Only a lower diastolic pressure was a significant predictor of race finishing (diastolic blood pressure 74-84 mmHg: adjusted odd ratio 3.81; 95\% confidence interval $[\mathrm{CI}]=1.09-13.27$ and diastolic blood pressure $<74 \mathrm{mmHg}$ : adjusted odd ratio $7.74 ; 95 \%$ $\mathrm{CI}=1.57-38.21)$ using the figure from the multivariable analysis. Among the finisher group, hemodynamic parameters showed statistically significant differences with lower systolic blood pressure $(135.9 \pm 14.8 \mathrm{mmHg}$ vs $119.7 \pm 11.3 \mathrm{mmHg} ; p<0.001)$, faster heart rate $(72.6 \pm 10.7 \mathrm{bpm}$ vs $96.4 \pm 10.4 \mathrm{bpm} ; p<0.001)$, lower stroke volume $(43.2 \pm 13.6 \mathrm{~mL}$ vs $29.3 \pm 10.1 \mathrm{~mL} ; p<0.001)$, higher stroke volume variation; median (interquartile range) (36\% [25\%-58\%] vs 53\% [33\%-78\%]; $p<0.001)$, and lower oxygen saturation $(97.4 \% \pm 1.0 \%$ vs $96.4 \% \pm 1.0 \% ; p<0.001)$. Systemic vascular resistance and cardian index did not change significantly.

Conclusion: The only race finishing predictor from the multivariable analysis was lower diastolic pressure. Finishers seem to have a hypovolemic physiologic response and a lower level of oxygen saturation.

Keywords: running, physical endurance, athletic injuries, sports, athletic performance

\section{Introduction}

Ultra-trail running races have increased in popularity over the last few years. ${ }^{1,2}$ This kind of race has several unique characters including a prolonged race period, specifically a distance of at least $50 \mathrm{~km}$, and a high elevation route with rough terrain. Many recent studies have documented cardiac damage and pulmonary function deterioration after prolonged exercise, even in healthy runners. ${ }^{3-6}$ Most of these studies focused mainly on flat-terrain running, in particular marathons. Standard long distance running races 
usually use easily accessible courses which are completely different from the more challenging variable terrain involved in trail running. This kind of sport requires extreme endurance despite the perceived low peak performance, which could make a significant difference when it is compared to high-strenuous, shorter duration competitions. With a recent increase in its popularity, many runners try to participate in this extreme sport, which results in a large heterogeneity of athletes competing, from elite runners to recreational individuals. ${ }^{1}$ Concerns regarding the suitability of the candidates make it difficult for the organizers to manage the race and put in place adequate safety regulations for the whole gamut of competitors. It is a standard rule for the trial course to have many checkpoints and food services along the course; however, the distance between each checkpoint is usually more than an hour. Organizers always brief the runners about the basic safety needs specific to the course, but the possibility of injuries throughout the race is an unpredictable factor. The main concern for the organizers is the safety of runners because the routes often run deep into forested area and access is difficult if any medical problems occur.

The noninvasive ultrasonic flow measurement (USCOM; Sydney, Australia) is an advanced hemodynamic assessment method with reliable accuracy when compared to other standard methods and has been validated by many previous publications..$^{7-10}$ This is a noninvasive assessment which will not impair the performance of the runners before and after the race. This study was conducted to identify race predictors which could predict the race results and classify the runners allowing better safety management during the race and also to evaluate the physiologic effects of prolonged endurance physical exercise with a noninvasive flow assessment method.

Our hypothesis was that there is an association between gender, body mass index, training data, and heart rate and race performance, and we expected the hemodynamic change to be in accordance with hypovolemic change such as tachycardia, lower blood pressure, and higher stroke volume variation (SVV) after finishing the race.

\section{Methods}

This study was approved by the institutional review board and ethics committee of the Faculty of Medicine, Chiang Mai University, Chiang Mai, Thailand. The prospective observational study was conducted during the Pong Yaeng trail race on November 12, 2016. All runners were voluntarily invited to enroll onto this study without any exclusions.

\section{The race}

The $66 \mathrm{~km}$-Pong Yaeng trail race is one of the most popular trail races in Thailand and is approved by the International Trail Running Association. The 66k-route takes the runners through a mixture of deciduous and pine forests along the old paths connecting the villages of the Pong Yaeng subdistrict, gaining an elevation of more than $3,400 \mathrm{~m}$. The time limit is 17 hours.

\section{Questionnaire and measurement}

Informed written consent was obtained from each participant. All subjects answered the research questionnaire, including details such as the basic data (age, gender, bodyweight, height, medical history), running experience, and running records (fastest 10, 21 and $42 \mathrm{~km}$ records). Predicted maximal oxygen consumption values were obtained from running smartwatches which provide this function. The prerace assessment was carried out during the registration process 1 day before the race. All participants had hemodynamic parameters assessed, including blood pressure $(\mathrm{mmHg})$ using a standard semi-automatic oscillometric blood pressure measurement device and oxygen saturation $\left(\mathrm{SaO}_{2} ; \%\right)$ using a noninvasive fingertip pulse oximeter. Other hemodynamic parameters including heart rate (beats/min), stroke volume $(\mathrm{SV} ; \mathrm{mL}), \mathrm{SVV}(\%)$, cardiac index $\left(\mathrm{CI} ; \mathrm{L} / \mathrm{min} / \mathrm{m}^{2}\right)$, and systemic vascular resistance (SVR; dynes $/ \mathrm{sec} / \mathrm{cm}^{5}$ ) were obtained using an USCOM device. The probe of the machine was applied at the suprasternal notch while the participant was in a sitting position until an adequate flow pattern was achieved. The operators were well trained physicians and familiar with this assessment. The ultrasonic flow measurement takes less than 5 minutes to complete the assessment.

All runners competed over the same course and in the same weather conditions. Water and food services were supplied adequately along the course. The time limit for completion of the course was 17 hours. The finishers were reassessed using the same methods after crossing the finish line and having a specific resting period, but the postrace assessments were done within 15 minutes of finishing the race. The same methods were used as in the prerace assessment. Finishing times were individually recorded by the race organizer. The runners who did not finish were not assessed after the race. The runners were divided into two groups: finishers (runners who crossed the finish line) and nonfinishers (runners who did not cross the finish line).

The noninvasive flow measurement (USCOM) was chosen to measure the hemodynamic parameters in this study because 
of its simplicity, completely noninvasive technique, and its ability to record a wide variety of hemodynamic parameters. ${ }^{9}$ Previous studies have validated the accuracy of this method and have shown that it is highly accurate against other standard hemodynamic assessment techniques; this technique has also been applied in many clinical applications with critical patients. ${ }^{7,8,10}$ This noninvasive method is the most reasonable test for runners in both a pre- and postrace assessment setting.

\section{Statistical analysis}

Statistical analysis was performed using STATA version 14.0 (StataCorp, College Station, TX, USA). Categorical variables are presented as numbers and percentages, and comparison between groups was made using Fisher's exact test. Continuous variables are presented as median and interquartile ranges (IQR) or mean and standard deviation (SD), and comparison between groups was made using a Student's $t$-test or a
Wilcoxon rank-sum test. Race predictors were determined by univariable and multivariable logistic regression analysis. Statistical significance was established at $p<0.05$.

\section{Results}

289 runners were registered for this race, but 61 runners did not present at the start line, leaving 228 runners who actually competed in the race. The average age was 37 years (range 24-56 years). 163 out of the $228(71.5 \%)$ runners were male. 130 out of the $228(57.0 \%)$ participants answered the questionnaire before the race. 126 out of $228(55.3 \%)$ subjects completed the prerace hemodynamic assessment, and all of this group also completed the questionnaire. 189 out of 228 (82.9\%) runners crossed the finish line. The average finishing time was 920 (449-1,020) minutes. 36 out of 189 (19\%) finishers completed the postrace hemodynamic assessment. A summary showing the numeric distribution of the runners is described as Figure 1.

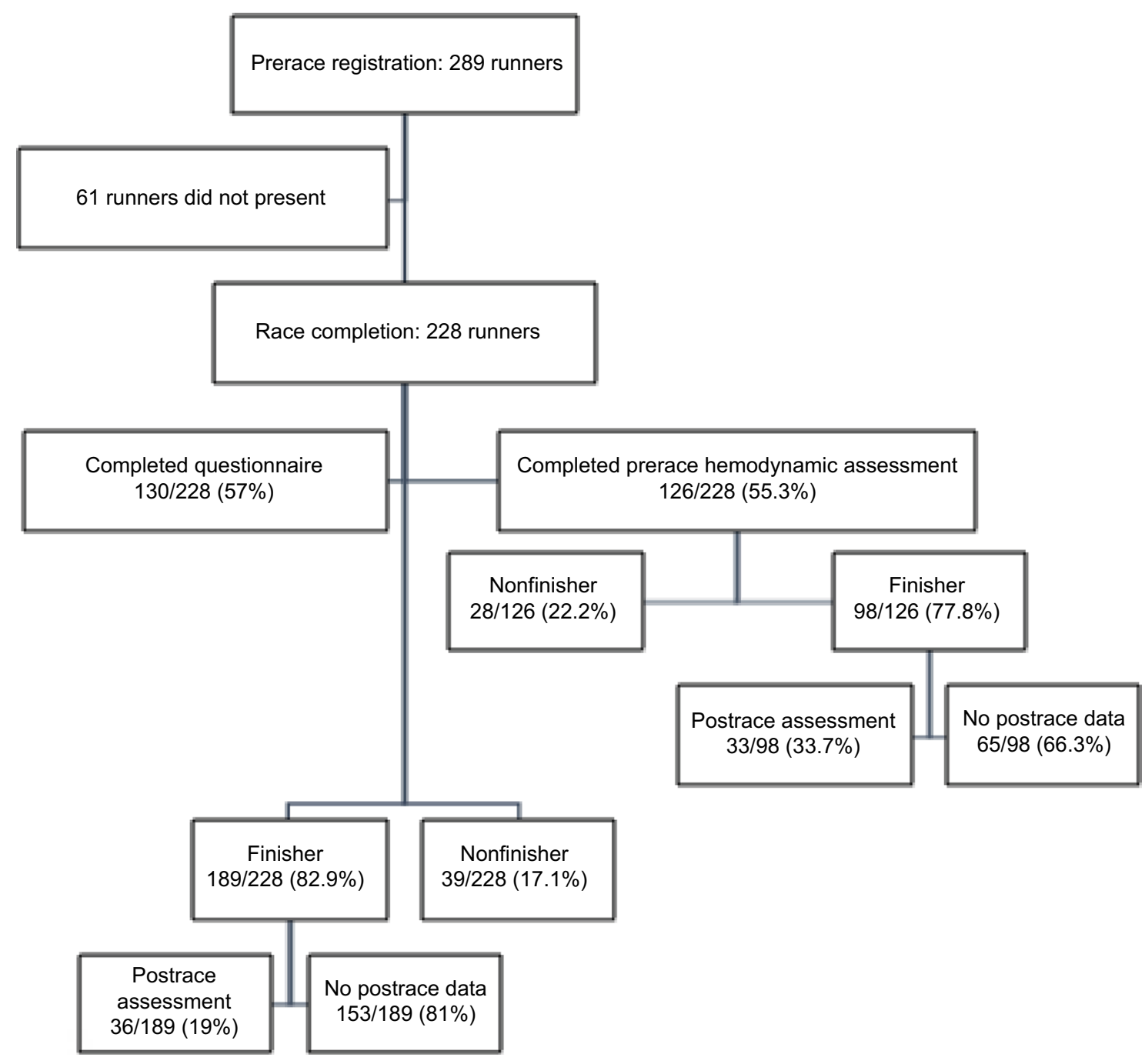

Figure I Flow chart demonstrates the complete data of participants. 
Univariable analysis showed that the following factors were more likely to be associated with crossing the finish line: male gender, longest distance ever run, better running records at every distance $(10,21,42 \mathrm{~km})$, and a lower diastolic blood pressure (DBP) (Tables 1 and 2).

The multivariable analysis, as shown in Table 3, indicated that lower diastolic pressure was the only significant predictor for crossing the finish line. After dividing the range of diastolic pressure into three groups, according to percentile, it was clear that the runners with a lower prerace diastolic pressure have a higher chance of finishing the race (DBP 74-84 mmHg: adjusted odd ratio 3.81; 95\% CI $=1.09-13.27$ and DBP <74 mmHg: adjusted odd ratio 7.74; $95 \% \mathrm{CI}=1.57-38.21$ ). However, for only 110 subjects out of 126 runners we had complete data, including both the basic data from the questionnaire and prerace hemodynamic assessments. This therefore was the only data included in the

Table 3 Multivariable analysis for race predictors $(n=\mid 10)$

\begin{tabular}{llll}
\hline Variables & OR & $\mathbf{9 5 \% ~ C l ~}$ & p-value \\
\hline Male & 2.02 & $0.57-7.10$ & 0.275 \\
Longest distance & 1.02 & $0.99-1.05$ & 0.237 \\
Best I0 km record & 1.00 & $0.93-1.07$ & 0.967 \\
Best $21 \mathrm{~km}$ record & 0.97 & $0.92-1.01$ & 0.148 \\
Best $42 \mathrm{~km} \mathrm{record}$ & 1.00 & $0.98-1.02$ & 0.839 \\
DBP $>84 \mathrm{mmHg}$ & 1.0 & Reference & \\
DBP 75-84 mmHg & 3.81 & $1.09-13.27$ & 0.036 \\
DBP $<75 \mathrm{mmHg}$ & 7.74 & $1.57-38.21$ & 0.012 \\
\hline
\end{tabular}

Abbreviations: OR, odds ratio; $\mathrm{Cl}$, confidence interval; DBP, diastolic blood pressure.

Table I Univariable analysis for race predictors from demographic data, running experience, and running records

\begin{tabular}{|c|c|c|c|c|}
\hline Variables & Total n (\%) & Finishers $(n=189)$ & Nonfinishers $(n=39)$ & $p$-value \\
\hline Age (years), mean $\pm S D$ & $228(100)$ & $37.0 \pm 7.8$ & $35.8 \pm 8.0$ & 0.393 \\
\hline Gender, n (\%) & & & & 0.022 \\
\hline Female & $65(28.5)$ & $48(25.4)$ & $17(43.6)$ & \\
\hline Male & $163(7 \mid .5)$ & I4I (74.6) & $22(56.4)$ & \\
\hline Body weight $(\mathrm{kg})$, mean \pm SD & $130(57.0)$ & $64.9 \pm 10.6$ & $67.3 \pm 13.1$ & 0.302 \\
\hline Height $(\mathrm{cm})$, mean $\pm S D$ & $130(57.0)$ & $169.2 \pm 7.3$ & $168.6 \pm 9.5$ & 0.789 \\
\hline BMI $\left(\mathrm{kg} / \mathrm{m}^{2}\right)$, mean $\pm \mathrm{SD}$ & $130(57.0)$ & $22.6 \pm 2.7$ & $23.5 \pm 3.3$ & 0.112 \\
\hline Experience (years) & $127(55.7)$ & & & \\
\hline Median (IQR) & & $2(2-3)$ & $2(2-3)$ & 0.289 \\
\hline Min-max & & $\mathrm{I}-25$ & $\mathrm{I}-33$ & \\
\hline Marathon finisher, n (\%) & $127(55.7)$ & & & 0.964 \\
\hline No & $9(7.1)$ & $7(7.1)$ & $2(6.9)$ & \\
\hline Yes & $118(92.9)$ & $91(92.9)$ & $27(93.1)$ & \\
\hline 50 km finisher, $\mathrm{n}(\%)$ & $126(55.3)$ & & & 0.877 \\
\hline No & $39(31.0)$ & $30(30.6)$ & $9(32.1)$ & \\
\hline Yes & $87(69.0)$ & $68(69.4)$ & $19(67.9)$ & \\
\hline Longest distance $(\mathrm{km})$, mean $\pm \mathrm{SD}$ & $123(53.9)$ & $56.4 \pm 23.8$ & $45.6 \pm 15.6$ & 0.026 \\
\hline Best $10 \mathrm{~km}$ record $(\mathrm{min})$, mean $\pm S D$ & $126(55.3)$ & $55.8 \pm 9.9$ & $62.5 \pm 9.6$ & 0.002 \\
\hline Best $21 \mathrm{~km}$ record $(\mathrm{min})$, mean $\pm S D$ & $124(54.4)$ & $125.0 \pm 20.5$ & $143.4 \pm 22.6$ & $<0.001$ \\
\hline Best $42 \mathrm{~km}$ record $(\mathrm{min})$, mean $\pm S D$ & $116(50.9)$ & $292.8 \pm 46.2$ & $326.8 \pm 36.5$ & $<0.001$ \\
\hline Finish time $(\mathrm{min})$ & $189(100)$ & & & \\
\hline Median (IQR) & & 920 (798-977) & & \\
\hline Min-max & & $449-1,020$ & & \\
\hline
\end{tabular}

Abbreviations: BMI, body mass index; IQR, interquartile range; SD, standard deviation.

Table 2 Univariable analysis for race predictors from prerace hemodynamic parameters

\begin{tabular}{|c|c|c|c|c|}
\hline Variables & Total n (\%) & Finishers $(n=189)$ & Nonfinishers $(n=39)$ & $p$-value \\
\hline $\mathrm{VO}_{2} \max (\mathrm{L} / \mathrm{min})$, mean $\pm \mathrm{SD}$ & $43(18.9)$ & $44.4 \pm 3.9$ & $41.4 \pm 1.8$ & 0.055 \\
\hline $\mathrm{SBP}(\mathrm{mmH})$, mean $\pm \mathrm{SD}$ & $126(55.3)$ & $135.3 \pm 14.8$ & $136.7 \pm 21.2$ & 0.699 \\
\hline $\mathrm{DBP}(\mathrm{mmHg})$, mean $\pm \mathrm{SD}$ & $126(55.3)$ & $78.1 \pm 9.8$ & $82.6 \pm 12.7$ & 0.047 \\
\hline $\mathrm{HR}$ (beats/min), mean $\pm \mathrm{SD}$ & $126(55.3)$ & $74.9 \pm 11.9$ & $78.9 \pm 14.6$ & 0.134 \\
\hline $\mathrm{SV}(\mathrm{mL})$, mean $\pm \mathrm{SD}$ & $125(54.8)$ & $40.2 \pm 13.4$ & $35.9 \pm 9.8$ & 0.120 \\
\hline $\mathrm{SVV}(\%)$, mean $\pm \mathrm{SD}$ & $125(54.8)$ & $50.9 \pm 35.4$ & $41.0 \pm 29.9$ & 0.180 \\
\hline $\mathrm{Cl}\left(\mathrm{L} / \mathrm{min} / \mathrm{m}^{2}\right)$, median (IQR) & $125(54.8)$ & $2.6(2.1-3.5)$ & $2.7(2.2-3.1)$ & 0.917 \\
\hline SVR $\left(\right.$ dynes $\left./ \mathrm{sec} \mathrm{cm}^{-5}\right)$, mean \pm SD & $125(54.8)$ & $3,167.1 \pm 1,159.2$ & $3,385.0 \pm 1,365.4$ & 0.402 \\
\hline $\mathrm{SaO}_{2}(\%)$, mean $\pm \mathrm{SD}$ & $126(55.3)$ & $97.1 \pm 1.3$ & $96.7 \pm 1.2$ & 0.133 \\
\hline
\end{tabular}

Abbreviations: $\mathrm{VO}_{2}$ max, maximal oxygen consumption; SBP, systolic blood pressure; DBP, diastolic blood pressure; HR, heart rate, SV, stroke volume; SVV, stroke volume variation; $\mathrm{Cl}$, cardiac index; $\mathrm{SVR}$, systemic vascular resistance; $\mathrm{SaO}_{2}$, oxygen saturation. 
performance of the multivariable analysis. We did not use the multiple imputation method to correct the data, despite the data set being incomplete. This was because there was so much missing data that an error in the analysis would have been inevitable.

Out of the 33 subjects who underwent the postrace hemodynamic assessment, systolic blood pressure, heart rate, and SVV were significantly increased in the postrace status compared with prerace status, whereas $\mathrm{SV}$ and $\mathrm{SaO}_{2}$ were decreased. The remaining hemodynamic parameters were not significantly changed (Table 4).

\section{Discussion}

Ultra-distance trail running has several unique characters that raise numerous special concerns for the race organizer. Although the International Trail Running Association was established to control and regulate every official trail running race around the world, the health policy of this association is mainly focused on individual prerace athletes' health status and antidoping objectives. From a review of relevant literature, no study has been conducted to determine race predictors concerning trail racing. The rationale behind the study is that if the organizers could predict the race results from the wide varieties of runners, they would be better able to arrange more effective safety management for the runners who are at greater risk of withdrawal from the race.

From the results of the univariable analysis, the only significant predictor from the basic demographic data is male gender. $86.5 \%$ ( 141 out of 163 ) of male runners finished the race, while only $73.8 \%$ (48 out of 65 ) of female runners were finishers. The age, weight, and body mass index could not be used to predict the race results. In this study, the questionnaire regarding running experience included the number of years the participant had been running and the race finishing history of a standard marathon race and a $50 \mathrm{~K}$ trail race. None of the experience data achieved a level of statistical significance. The distance run- ning records, however, showed a level of statistical significance in every field including the longest distance ever run and the best records at every distance $(10 \mathrm{~km}, 21 \mathrm{~km}$, and $42 \mathrm{~km})$. The finishers had a record of longer runs than the nonfinishers by a distance of nearly $11 \mathrm{~km}(56.4 \pm 23.8 \mathrm{~km}$ in the finisher group and $45.6 \pm 15.6 \mathrm{~km}$ in nonfinisher group; $p=0.026$ ) and also faster times at every distance. These parameters could probably be explained by the fact that the finishers had undergone better training and had higher fitness levels than the nonfinishers. These findings was confirmed in the study by Knechtle et al, ${ }^{11}$ which investigated the race performance in recreational ultrarunners in a 24-hour run. They concluded that the personal best marathon time and the longest training run, not anthropometry such as skinfold thickness or body mass index, predicted the race performance. Considering these findings, we might assume that training factors are more important than body geometry, especially in ultra-distance runners.

The prerace hemodynamic parameters, as shown in Table 2, showed DBP as the only race finish predictor from the result of the multivariable analysis. The finisher group had a lower DBP than the nonfinisher group. Blood pressure in athletes has been reviewed intensively. A meta-analytical study carried out by Berge et al ${ }^{12}$ in 2014 reviewed 16 studies that included nonathletes as controls and showed, contradictorily, that blood pressure was lower in athletes than in controls in 9 studies and higher in athletes in 7 studies. The conclusion was that there was no significant difference in blood pressure between athletes and controls. However, most of studies in this meta-analysis were conducted among elite athletes. When comparing this study to ours, in which the participants have such a mix of training levels, this finding is hard to rationalize due to the wide variation of fitness among the athletes. Several studies in this meta-analysis reported that blood pressure in athletes who had trained $>10$ hours/wk was higher than in those who had trained less. On the other hand, the American Heart Association lifestyle management guidelines in 2013

Table 4 Hemodynamic parameter comparison pre- and postrace

\begin{tabular}{|c|c|c|c|c|}
\hline Parameters & $\mathbf{N}$ & Prerace & Postrace & p-value \\
\hline $\mathrm{SBP}(\mathrm{mmHg})$, mean $\pm \mathrm{SD}$ & 33 & $|35.9 \pm| 4.8$ & $119.7 \pm 11.3$ & $<0.001$ \\
\hline $\mathrm{DBP}(\mathrm{mmHg})$, mean $\pm \mathrm{SD}$ & 33 & $76.6 \pm 10.1$ & $73.1 \pm 6.8$ & 0.066 \\
\hline $\mathrm{HR}$ (beats/min), mean $\pm \mathrm{SD}$ & 33 & $72.6 \pm 10.7$ & $96.4 \pm 10.4$ & $<0.001$ \\
\hline $\mathrm{SV}(\mathrm{mL})$, mean $\pm \mathrm{SD}$ & 33 & $43.2 \pm 13.6$ & $29.6 \pm 10.4$ & $<0.001$ \\
\hline SVV (\%), median (IQR) & 33 & $36(25-58)$ & $53(33-78)$ & $<0.001$ \\
\hline $\mathrm{Cl}\left(\mathrm{L} / \mathrm{min} / \mathrm{m}^{2}\right)$, mean $\pm \mathrm{S} \mathrm{D}$ & 33 & $3.0 \pm 1.0$ & $2.8 \pm 0.9$ & 0.583 \\
\hline SVR (dynes $\left./ \mathrm{sec} \mathrm{cm}^{-5}\right)$, mean $\pm \mathrm{SD}$ & 33 & $3,044 \pm 1,052.8$ & $2,888.0 \pm 871.8$ & 0.431 \\
\hline $\mathrm{SaO}_{2}(\%)$, mean $\pm \mathrm{SD}$ & 31 & $97.4 \pm 1.0$ & $96.4 \pm 1.0$ & $<0.001$ \\
\hline
\end{tabular}

Abbreviations: SBP, systolic blood pressure; DBP, diastolic blood pressure; HR, heart rate; SV, stroke volume; SVV, stroke volume variation; $\mathrm{Cl}$, cardiac index; SVR, systemic vascular resistance; $\mathrm{SaO}_{2}$, oxygen saturation. 
still advised adults to engage in aerobic physical activity to lower blood pressure, advice being: 3-4 sessions a week, lasting on average 40 minutes per session, and involving moderate-to-vigorous intensity physical activity. ${ }^{13}$ From our point of view, the lower DBP in our data could be as a result of the exercise effects on amateur athletes which is different from the elite athlete group according to the meta-analysis data. According to the multivariable analysis, only lower DBP is a statistical significant race predictor. However, only 110 subjects in our study had completed all sections of the prerace data for the performance of this analysis.

The effects of ultra-endurance physical exercise on hemodynamic and pulmonary function have been described in many previous studies. ${ }^{5,14-16}$ From the hemodynamic results in our study, systolic blood pressure, heart rate, and SVV were significantly increased, while stroke volume was significantly reduced but SVR and CI did not change. These findings could be interpreted as the results of hypovolemia, which has a physiologic response by lowering systolic pressure, initiating tachycardia, and lowering SV. However, these standard parameters are poor markers of hypovolemia. ${ }^{17} \mathrm{SVV}$ is one of the dynamic markers which has been shown as being superior to static markers in predicting fluid responsiveness. ${ }^{18}$ In this study, the SVV was statistically significantly higher after the race. This may confirm the effects of hypovolemia that occurred in the runners even though the athletes were allowed to hydrate at will during the race. However, there are numerous limitations of SVV in clinical usage such as the need for mechanical ventilation in order to achieve complete controlled ventilation without spontaneous breathing and the control of tidal volumes $(>8 \mathrm{~mL} / \mathrm{kg}$ ) without dysrhythmia. The CI did not change significantly; this is a result of the normal physiologic compensation of the body by driving the heart rate to compensate for the lower SV.

From our data, the runners had a lower $\mathrm{SaO}_{2}$ after finishing the race. The worsening pulmonary function after a prolonged endurance race has been described by many studies. Seedhouse et $\mathrm{al}^{16}$ has studied 8 triathletes competing in the 3-day World Ultraman Championships, and the results from the study showed that a reduction in peak expiratory flow, forced vital capacity, and forced expiratory volume in 1 second from baseline at the end of each race day. Rogers et $\mathrm{al}^{5}$ also found that lower $\mathrm{SaO}_{2}$, reduction of forced vital capacity (up to $22 \%$ ), and forced expiratory volume in 1 second decrease (up to $25 \%$ ) after finishing an Ultra-endurance multisport competition. The explanations for these findings were elusive. One of the possible causes is exercise-induced bronchospasm. The cause of this phenomenon would be from a cooled and dried airway caused by hyperventilation. It can occur in healthy individuals with no underlying pulmonary disorder and has a greater prevalence in elite athletes and those undergoing continuous high-intensity exercise. ${ }^{19}$ The most likely etiology of exercise-induced pulmonary dysfunction is exercise-induced noncardiogenic pulmonary edema from hyponatremia which will be spontaneously resolved when the initiated electrolyte disorder is corrected. ${ }^{19}$ This finding was also found by Zavorsky et $\mathrm{al}^{6}$ in their study focusing on marathon-induced lung edema, and they found that mild pulmonary edema occurs in at least $17 \%$ of subjects and it is not possible to predict the occurrence or severity of the edema. However, this physiologic change is usually mild in severity and does not affect the runner's performance.

This study is one of the very few studies that is focused on the ultra-trail running race using both historical data and basic demographic data along with the sophisticated biological data collected by noninvasive methodology. However, there are many limitations to this study. 130 out of $228(57.0 \%)$ volunteers answered the questionnaire; 120 out of 228 (52.6\%) participants had the hemodynamic flow assessment 1 day before the race; and only 39 out of 189 (20.6\%) finishers had the postrace assessment after crossing the finish line. This incomplete data collection may interfere with the statistical results of this study, and so the results may not be extrapolated to represent the whole of this population of runners. We cannot assess the hemodynamic change in the nonfinisher group due to the nature of the experimental design which did not include the monitoring of runners who withdrew from the race at any checkpoint along the course. We did believe that the USCOM would be the most appropriate noninvasive hemodynamic assessment tool for this situation, but there were several limitations to this device as its main clinical application is for fully sedated, critically ill patients under controlled ventilation condition, not for healthy spontaneously ventilated individuals.

The clinical implications of this study could be used by the race organizers who could use the significant univariable factor from the gender and the training factors to classify the runners into groups by predicted race finishing time. This would enable the targeting of the safety arrangements and the overall management of the trail race. The diastolic pressure is the sole significant factor from the multivariable analysis, but classification of the runners using this factor would be difficult with a single mean. However, it will be a field of great interest for the future research conducted specifically around this factor. Future research would be conducted with a slightly different study design and with an incentivized runner recruitment to avoid the large number of dropout participants. For improved physiologic assessment and 
monitoring, invasive assessments such as blood chemistry tests should be used and a specific volunteer control group must be assigned.

The race predictors from the univariable analysis included male gender, longest distance ever run, faster running records over specific distances $(10,21,42 \mathrm{~km})$, and lower diastolic pressure. However, from the multivariable analysis of the 40 runners included, the sole significant race predictor is lower diastolic pressure. From the hemodynamic data of 39 out of 189 (20.6\%) finishers, runners seem to have a hypovolemic physiologic response including lower systolic blood pressure, faster heart rate, lower SV, and higher SVV with exerciseinduced pulmonary injury which presented as lower oxygen saturation. The data from this study would help extreme sport organizers to prepare more safely for their races so that more appropriate medical service regulation for the competitors could be provided.

\section{Acknowledgment}

The authors would like to extend particular gratitude to Joan Peagam MSc (London), NPQH, from the Medical and Scientific English Language Consultancy, Chiang Mai University, for her gracious assistance with the English language editing of the final manuscript.

\section{Author contributions}

Study concept and design (N Taksaudom, N Tongsiri); obtaining funding; acquisition of the data (N Taksaudom, N Tongsiri, AP, CL, AC); analysis of the data (N Taksaudom, AT); drafting of the manuscript (N Taksaudom); critical revision of the manuscript (N Taksaudom, AT); approval of final manuscript (N Taksaudom, N Tongsiri, AT). All authors contributed toward data analysis, drafting and critically revising the paper and agree to be accountable for all aspects of the work.

\section{Disclosure}

The USCOM device was loaned free of charge by the Saint Medical Group Co. Ltd. Natee Tongsiri is the chief organizer of the Pong Yaeng $66 \mathrm{~km}$-ultra-trail race. The authors report no other conflicts of interest in this work.

\section{References}

1. A Special Report on Trail Running; 2010. Available from: http://www. outdoorfoundation.org/pdf/research.trailrunning.pdf.

2. Outdoor Recreation Participation; 2014. Available from: http://www. outdoorfoundation.org/pdf/ResearchParticipation2014.pdf.

3. Middleton N, George K, Whyte G, Gaze D, Collinson P, Shave R. Cardiac troponin $\mathrm{T}$ release is stimulated by endurance exercise in healthy humans. J Am College Cardiol. 2008;52(22):1813-1814.

4. Shave RE, Whyte GP, George K, Gaze DC, Collinson PO. Prolonged exercise should be considered alongside typical symptoms of acute myocardial infarction when evaluating increases in cardiac troponin $\mathrm{T}$. Heart. 2005;91(9):1219-1220.

5. Rogers IR, Speedy D, Hillman D, Noffsinger B, Inglis S. Respiratory function changes in a wilderness multisport endurance competition: a prospective case study. Wilderness Environ Med. 2002;13(2):135-139.

6. Zavorsky GS, Milne EN, Lavorini F, et al. Small changes in lung function in runners with marathon-induced interstitial lung edema. Physiol Rep. 2014;2(6):e12056.

7. Beltramo F, Menteer J, Razavi A, et al. Validation of an ultrasound cardiac output monitor as a bedside tool for pediatric patients. Pediatr Cardiol. 2016;37(1):177-183.

8. Chong SW, Peyton PJ. A meta-analysis of the accuracy and precision of the ultrasonic cardiac output monitor (USCOM). Anaesthesia. 2012;67(11):1266-1271.

9. Phillips RA, Smith BE, Madigan VM, et al. Assessment of the clinical utility of an ultrasonic monitor of cardiac output (the USCOM) and agreement with thermodilution measurement. Crit Care Resusc. 2010;12(3):209-213.

10. Thom O, Taylor DM, Wolfe RE, et al. Comparison of a supra-sternal cardiac output monitor (USCOM) with the pulmonary artery catheter. Br J Anaesth. 2009;103(6):800-804.

11. Knechtle B, Knechtle P, Rosemann T, Lepers R. Personal best marathon time and longest training run, not anthropometry, predict performance in recreational 24-hour ultrarunners. $J$ Strength Cond Res. 2011;25(8):2212-2218.

12. Berge HM, Isern $\mathrm{CB}$, Berge E. Blood pressure and hypertension in athletes: a systematic review. Br J Sports Med. 2015;49(11):716-723.

13. Eckel RH, Jakicic JM, Ard JD, et al. 2013 AHA/ACC guideline on lifestyle management to reduce cardiovascular risk: a report of the American College of Cardiology/American Heart Association Task Force on Practice Guidelines. Circulation. 2014;129(25 Suppl 2):S76-S99.

14. Jouffroy R, Caille V, Perrot S, Vieillard-Baron A, Dubourg O, Mansencal N. Changes of cardiac function during ultradistance trail running. $A m$ J Cardiol. 2015;116(8):1284-1289.

15. Klinkenberg LJ, Luyten P, van der Linden N, et al. Cardiac Troponin T and I release after a 30-km run. Am J Cardiol. 2016;118(2):281-287.

16. Seedhouse EL, Walsh ML, Blaber AP. Heart rate, mean arterial blood pressure, and pulmonary function changes associated with an ultraendurance triathlon. Wilderness Environ Med. 2006;17(4):240-245.

17. Michard F, Teboul JL. Predicting fluid responsiveness in ICU patients: a critical analysis of the evidence. Chest. 2002;121(6):2000-2008.

18. Maitland K, Levin M, English M, et al. Severe P. falciparum malaria in Kenyan children: evidence for hypovolaemia. QJM. 2003;96(6): 427-434.

19. Sanchez LD, Corwell B, Berkoff D. Medical problems of marathon runners. Am J Emerg Med. 2006;24(5):608-615.
Open Access Journal of Sports Medicine

\section{Publish your work in this journal}

The Open Access Journal of Sports Medicine is an international, peer-reviewed, open access journal publishing original research, reports, reviews and commentaries on all areas of sports medicine. The journal is included on PubMed. The manuscript management system is completely online and includes a very quick and fair

\section{Dovepress}

peer-review system. Visit http://www.dovepress.com/testimonials.php to read real quotes from published authors. 